\title{
LA CONFORMACIÓN DE LA SUBJETIVIDAD ADOLESCENTE EN EL MARCO DEL MUNDO VIRTUAL ATRAVESADO POR LA PANDEMIA. ¿MALESTAR U OPORTUNIDAD? ¿ELECCIÓN O IMPOSICIÓN?
}

Alicia Costanzo

Psicóloga de la UCU Miembro Habilitante de AUDEPP Profesora titular del IUPA Correo electrónico: aliciacostanz@gmail.com ORCID: 0000-0001-8190-1895

Florencia Chabalgoity Arrambide Licenciada en Psicología de la UDELAR Miembro de AUDEPP Especialista en Psicoterapia Psicoanalítica del IUPA Profesora adjunta del IUPA Correo electrónico: fchabal@adinet.com.uy ORCID: 0000-0001-8504-0594 


\section{Resumen}

Partiendo de las fuentes que generan malestar en el ser humano, teorizadas por Freud, nos preguntamos qué entendemos actualmente por malestar. ¿Lo seguiremos planteando sobre los parámetros de represión de las pulsiones? Hoy podríamos pensarlo más como estar compelido a mostrarse, a habitar de alguna forma las redes, a fin de calmar la urgencia subjetiva. Los ideales sociales parecen incitar al despliegue de las pulsiones y a su exhibición, más que a su represión. ¿Qué consecuencias puede traer esto en el proceso de subjetivación?, en particular en el marco de una pandemia, cuando el recurso virtual se constituye en la única alternativa para todas las actividades.

La conformación de subjetividades adolescentes se dará en este contexto de incertidumbre y confinamiento o paulatino y parcial desconfinamiento. Las consecuencias de una suerte de endogamia sanitaria obligatoria a la que se ven enfrentados los adolescentes, con un tiempo vital «en pausa», aún no quedan claras. Los malestares señalados por Freud hace noventa años parecen quedar amplificados en el escenario actual. En el caso de esta franja etaria, la cuarentena pone más en evidencia aun que los vínculos con otros podrán fácilmente tornarse en fuentes potenciales de malestar.

Palabras clave: adolescencia, subjetividad, mundo virtual, malestar.

\section{The Conformation of Adolescent Subjectivity within the Framework of the Virtual World Crossed by the Pandemic. Discontent or Opportunity? Choice or Imposition?}

\section{Abstract}

Starting from the sources that generate discontent in the human being theorized by Freud, we wonder what we currently understand as discontent. Will we continue to relate it to the parameters of drive repressions? Today we could think of it more as being compelled to show oneself, to inhabit the networks in some way, in order to calm the subjective urgency. Social ideals seem to incite the spread of drives and their exhibition, rather than their repression. What consequences can this bring to the subjective process? Especially, within the framework of a pandemic when the virtual tool constitutes the only option for all activities.

The conformation of teenage subjectivities will take place in this context of uncertainty, confinement, or gradual and partial release.

The consequences of a sort of compulsory sanitary endogamy, which teenagers are facing, with vital moments "in standby", are still not clear. This discontent pointed out by Freud 90 years ago seems to be magnified in the current scenario. The quarantine exposes this even more, in the case of this age group, that the bonds with others, could easily become potential sources of discontent.

Keywords: adolescence, subjectivity, virtual world, discontent. 
El hombre ha llegado a ser... un dios con prótesis: bastante magnífico cuando se coloca todos sus artefactos, pero estos no crecen de su cuerpo y a veces aun le procuran muchos sinsabores.

Sigmund Freud (1974, p. 3034)

En El malestar en la cultura, Freud (1974) señalaba las tres fuentes del sufrimiento humano: «la supremacía de la Naturaleza, la caducidad de nuestro propio cuerpo» y la insuficiente regulación de «las relaciones humanas en la familia, el Estado y la sociedad» (p. 3011). El límite a las satisfacciones pulsionales derivadas de Eros y Tánatos, que pertenecer a la cultura impone, nos genera malestar.

\section{¿QUÉ ENTENDEMOS ACTUALMENTE POR MALESTAR?}

¿El malestar freudiano en la cultura sigue pudiendo plantearse sobre los parámetros de represión de las pulsiones? Hoy en día podríamos pensarlo más como el estar compelido a mostrarse, conectarse, habitar o visitar de alguna forma las redes, a fin de calmar la urgencia subjetiva, para ser alguien (existir) y para ser alguien para otro. ${ }^{1}$ Los ideales sociales actuales parecen incitar más al despliegue de las pulsiones y su eventual exhibición. ¿Qué consecuencias, entonces, puede traer esto en el proceso de subjetivación? ¿Cuáles serían hoy los márgenes, límites, en los cuales las pulsiones pueden ser desplegadas?

1 «Cuando miro se me ve, y por lo tanto existo» (Winnicott, 1986, p. 151). 
Las claves para descifrar lo bueno y lo malo, lo permitido y lo transgresor, se han visto transformadas. Estos parámetros, antes nítidos y consistentes, hoy se encuentran, al decir de Marcelo Viñar (2010), estallados, fragmentados, equívocos y ambiguos. El conflicto estaría puesto entre lo posible y lo imposible, más que entre lo permitido y lo prohibido, al haberse producido un cambio en los garantes metasociales, organizadores de nuestra mente (Viñar, 2010).

¿Y a partir de la pandemia? Lo imposible y ficcional se tornó posible y real. Lo ominoso y siniestro se hizo presente y borró los límites entre la fantasía y la realidad. Un enemigo invisible parece poner en juego lo más reprimido y oculto. $\mathrm{Y}$ al no poder representarlo, lo ligamos al otro, al cuerpo del otro, que se torna extraño y peligroso ya que nos puede contagiar (Ranzani, 2020). Es de suponer que esta nueva situación tendrá una incidencia en la conformación subjetiva: ¿implicará otra faceta de la mutación civilizatoria conceptualizada por Viñar (2010)?

María Cristina Rojas (2015) nos invita a concebir la subjetividad como «una subjetividad entramada, que va siendo/haciéndose con otros» (p. 88). Refiere a un psiquismo abierto que se constituye con y partir de los otros, y a una identidad en permanente construcción/deconstrucción.

Estos aportes de Viñar (2010) y Rojas (2015) nos conectan con los desarrollos de Paula Sibilia respecto a las mutaciones de las subjetividades. Esta autora refiere un nuevo fenómeno, la exhibición de la intimidad, que relaciona con las prácticas confesionales que reconfiguran los límites entre lo público y lo privado, y redefinen lo que entendemos hoy por intimidad (Sibilia, 2010). Apela al término extimidad ${ }^{2}$ para dar cuenta de una intimidad que se exhibe, «un festival de vidas privadas» (Sibilia, 2010, p. 15).

2 Extimidad (extimité) es un neologismo creado por Jacques Lacan en su seminario sobre la ética del psicoanálisis, de 1958. Lo éxtimo, para Lacan, es precisamente lo más íntimo, que a su vez está en el exterior, como un cuerpo extraño (García, 2017). Sibilia (2010) le da a este término un nuevo sentido para dar cuenta de un fenómeno contemporáneo. 
Entiende a «esas nuevas prácticas como un síntoma de mutación y de transformación histórica en las subjetividades» (p. 17). Nos acerca la idea de que estaríamos en una transición en la cual lo que está cambiando es ese yo que protagoniza el relato de la propia vida y crea un tipo de sujeto distinto, el que hace del yo «un show [...] un espectáculo visible» (p. 19).

Esta autora retoma el concepto de sociedad del espectáculo de Guy Debord para dar cuenta de la espectacularización de la vida cotidiana, donde las subjetividades se construyen y se realizan en el campo de lo visible (en conexión permanente), desplazándose así desde la propia interioridad a la superficie observable (Sibilia, 2010). Las diferencias entre realidad y ficción, entre máscara y realidad o auténtico y falso tienden a difuminarse. Emerge el personaje o, mejor, su superficie. Alguien que está siempre a la vista, que necesita tener público, lectores, miradas, para no dejar de existir. Pareciera que nos estamos convirtiendo en la máscara misma, en personajes audiovisuales, subjetividades más funcionales para habitar nuestro mundo contemporáneo (Sibilia, 2010).

Las formas de residir en el universo virtual pueden incluso llegar a una suerte de exhibicionismo digital. Este se define como «la tendencia por parte de algunas personas de mostrar su vida personal sin demora y de manera recurrente e insistente y así obtener refuerzo social» (Psicosol, 2016, párr. 4), pero a costa de la pérdida de espontaneidad. «La meta del exhibicionista digital no es la excitación sexual, sino la aprobación, el [h]alago, la alabanza, el aplauso y, en definitiva, el refuerzo social» (Psicosol, 2016, párr. 8). En caso de no conseguirlo, se generaría pérdida de autoestima para el sujeto que, eventualmente, podría derivar en depresión. En la adolescencia, podríamos pensar que este exhibicionismo estaría tanto al servicio de una búsqueda de reaseguros narcisistas, puestos en jaque a partir de los cambios y duelos típicos de esta edad, como — más específicamente- de la apropiación de un cuerpo en cambio. Y esto acontece fundamentalmente a través de la mirada (comentarios, likes, etc.) que devuelven las redes, 
al modo del espejo de la bruja de «Blanca Nieves». Si bien pensamos que priman los aspectos narcisistas, es difícil deslindarlos de la satisfacción sexual, tanto de la autoerótica como de los intentos de posicionarse como objeto de deseo para otros.

Las nuevas subjetividades mediáticas se nos presentan más bien inestables, precarias, fluidas, en comparación a las sólidas subjetividades estatales de antaño; nuevas subjetividades socialmente instituidas por los discursos, que - en tanto contenidos, representaciones y prácticastienen efectos reales sobre los individuos. El discurso mediático produce fugacidad, «actualidad, imagen, opinión» (Corea y Lewkowicz, 2013, p. 48). Basta pensar en la proliferación de videos de TikTok y en los desafíos (challenge) que han surgido en los últimos meses, en el marco de una humanidad que se ha visto sacudida de manera casi simultánea por una pandemia.

Una nueva consigna se nos ha propuesto, desde todos los medios y casi todos los países, para afrontar el peligro de la poco conocida coviD-19: "Quedate en casa». La cuarentena voluntaria (es el caso de Uruguay) u obligatoria conlleva cambios en los modos de trabajo, estudio y relacionamiento. La percepción de los demás —alejarse para cuidarnos y cuidarlos- fácilmente puede deslizarse al peligroso territorio del otro como potencial enemigo.

Esta situación convirtió a muchas de nuestras ciudades (y esto se replicó a escala planetaria) en escenarios de ficción: calles vacías, con animales salvajes que se aventuraban a explorar territorios urbanos, la mayoría de los comercios cerrados, los eventos, espectáculos y reuniones públicas prohibidas. Los habitantes comenzaron a circular con tapabocas y con sensación de miedo o culpa por estar en la calle, sobre todo al principio de la llegada del virus.

Nuestra percepción del tiempo también se vio alterada. Esta categoría tan subjetiva se nos impuso, sobre todo al principio, como una 
vivencia de estar en pausa. Un tiempo escandido entre informes oficiales de cifras de avance de la pandemia a nivel nacional y a nivel mundial: el manejo sanitario y las consecuencias económicas. Casi nada más parece ocurrir. Un tiempo colmado de información de calidad variada, a veces contradictoria: desde apelaciones al miedo hasta a la responsabilidad individual y colectiva; de crisis no solo sanitaria; de la amenaza de penurias a la constatación dramática, en ocasiones, del efecto general de empobrecimiento.

¿Qué subjetividad se gesta en la incertidumbre, tanto del confinamiento como en la del paulatino (limitado) desconfinamiento? ¿Y particularmente en el caso de los adolescentes?

\section{LA CONFORMACIÓN DE LAS SUBJETIVIDADES EPOCALES ADOLESCENTES Y EL MALESTAR}

... si la transición adolescente trabaja en el sentido de la autonomización, junto a esto ha de procesar el reconocimiento de ser uno con otros y entre otros [...]. Toda autonomía es interdependiente y no somos por fuera de los lazos con otros. (Rojas, 2015, p. 99)

Un otro que se impone con su deseo, otredad y ajenidad, y exige un trabajo de elaboración de las diferencias. Este ir siendo del que nos habla Rojas (2015), ¿cómo se procesa en pandemia?

Frente a la imposibilidad del encuentro cuerpo a cuerpo, ¿cómo se tramita la condición adolescente ${ }^{3}$ en las redes y el mundo digital? Lo virtual, recurso potencialmente valioso de gestión de la conflictiva

3 La condición adolescente se conceptualiza como una producción cultural de la modernidad. Se encuentra indisolublemente ligada al perfil que vayan adoptando las configuraciones familiares en un determinado momento histórico (Cao, 2009). 
adolescente, pasa a tornarse casi la única manera posible de hacerlo. ¿Les es suficiente? ¿Qué consecuencias tendrá esta hiperconectividad cuando el contacto social, el estudio, el trabajo y el ocio quedan reducidos exclusivamente al recurso virtual?

Las pantallas no compensan totalmente la falta de encuentro presencial. La sensación de soledad, la tristeza y la ansiedad en algún momento surgen, ya que los adolescentes necesitan abrazarse, tocarse, moverse, como nos recuerda Liliana Szapiro (en Ranzani, 2020).

El malestar se define comúnmente como una sensación física de indisposición y molestia general e imprecisa. Una sensación de inquietud y desazón que se siente ante un acontecimiento considerado de forma negativa. ¿Cómo pensar esto a partir del coronavirus? ¿Qué pasa con la incertidumbre, la ansiedad, con el miedo al otro? ¿Acaso algo de esta sensación vaga e indefinible no es la que siente usualmente el púber frente a los cambios corporales o el adolescente frente a las turbulencias identificatorias? ¿Las exigencias de lo social y cultural han incrementado este malestar? ¿Y el encierro impuesto?

El escenario virtual tal vez permita transitar las urgencias identificatorias y vinculatorias (Cao, 2009) y estos malestares al amparo de los otros, que aportan escucha y mirada en momentos de desamparo, incertidumbre y pérdida. El espacio cibernético se habitará, utilizará, compartirá desde la singularidad de cada historia de vida. Pero reiteramos las preguntas: ¿qué sucede cuando estas urgencias se transitan en el encierro?, ¿será suficiente este recurso virtual si se constituye en el único disponible?

En el marco de la pandemia, habría que estar atentos a la posibilidad de que se genere

un repliegue narcisista (aumento de las horas de sueño, humores ciclotímicos, sobreaislamiento, aburrimiento, intolerancia) o un efecto regresivo (una sobresaturación de los modelos y puntales que vino 
proveyendo el imaginario familiar, junto con una reedición edípica que no aligera su peso con la descarga extramuros del hallazgo de objeto). (Cao, 2020, pp. 57-58)

Basta remitirse a los discursos de los pacientes adolescentes o jóvenes en la consulta: «Es como cuando era más chico, todos en casa, cenando con papá y mamá, extraño llegar tarde a la noche de clases...», «Hoy me sentí un poco mejor porque pude ver a una amiga, jme cambió el día!», «jNunca pensé que fuera a extrañar ir al liceo!».

¿Cómo se ven alteradas las experiencias novedosas de estas etapas: el ingreso a secundaria, la interrupción o desfasaje de los festejos de los cumpleaños de 15 , las primeras previas y salidas nocturnas, el viaje y fiesta de egreso del liceo, el inicio de la vida universitaria?

Esta situación podrá afectar, eventualmente, «la búsqueda de nuevos equilibrios para la autoestima, incrementando el desorden narcisista transitorio y genérico ${ }^{4}$ que padecen» (Cao, 2009, p. 17). En algunos casos, incluso, «la ausencia de experiencias impedirá el acceso a los logros que puedan cimentarla [...] así el proyecto a futuro tambaleará [...] sin logros concretos que alimenten la autoestima, el futuro [podrá quedar] reducido al terreno de la fantasía» (Cao, 2020, p. 57). Serán nuevos duelos a transitar, encontrando alternativas, mientras se logra recatectizar el futuro. «Mis hijas estaban tan felices de volver al liceo, ¡como si se hubieran ganado un viaje a Disney!», «Me invitaron a otra huevada por el cumple de $X$. ¡Es la tercera ya! ¡Ella pensó que ya nos habíamos olvidado! ¡Estaba refeliz! ¡No pensé que me gustaran tanto!».

4 El desorden narcisista transitorio y genérico en la adolescencia se origina cuando, al abandonar la infancia, el sujeto pierde no solo sus recursos, sino también su estructura psíquica, que laboriosamente construyó (Cao, 2009). 


\section{URGENCIA Y MALESTAR EN EL CUERPO PUBERAL: ¿CUÁNTO PUEDE FAVORECER U OBTURAR SU VIVENCIAR EN LAS REDES?}

La adolescencia exige al niño que se convierte en púber un trabajo psíquico trascendental para integrar la novedad de las transformaciones corporales. Uno de los desafíos de esta etapa es transitar estos cambios «preservando al mismo tiempo una cierta continuidad en el sentimiento de existir: cambiar siendo el mismo» (Marty y Missonnier, 2010-2011, párr. 19).

Nos cuestionamos cómo hace el púber para incorporar la novedad y preservar la continuidad en un contexto de pandemia. ¿Acaso las vivencias propias de este período evolutivo no han de ser también las que se experimentan frente al virus?, vivencias de ser arrasado-amenazado, de irrupción de lo desconocido, de imposibilidad de control, de robo, incertidumbre, falta de garantías, miedos y ansiedades.

¿Cómo se puede tramitar la sexualidad en el encierro, endogámico y familiar? Rojas (2015) nos recuerda que «la sexualidad se conforma dentro de los modos de lazo con el otro y los códigos propios de la época [...] la sexualidad es una producción propia de cada tiempo» (pp. 96-97). ¿Cómo se irá conformando en tiempo de coronavirus?, ¿dependerá de cuánto se extiendan sus limitaciones? ¿Es posible la esperable dematernalización del cuerpo (Le Breton, 2014) cuando se compele a los púberes a una suerte de endogamia sanitaria obligatoria?

La realidad virtual posibilitaría sobrevivir a la violencia de la metamorfosis que se produce en este período, soportar ser transformado sin posibilidad real de control. Este medio puede constituirse en un campo privilegiado de ensayo, experimentación y anticipación en tanto posibilidad de exploración de un nuevo mundo a partir de una nueva autonomía, al modo de lo que Ricardo Rodulfo (2012) llama la etapa de la segunda deambulación (retorno a lo exploratorio, independencia de movimientos 
que ganan la calle y la noche, nuevo distanciamiento-extrañamiento de lo familiar, etc.). Solo que aquí se da sin salir de casa, sin el contacto potencialmente perturbador del cuerpo a cuerpo real, con otro.

En la actualidad se incita a quedarse en casa ya no como elección, sino como indicación o - en algunos países- como imposición. El cuerpo pubertario es pasible de ser dañado, afectado, invadido por un virus. «El cuerpo es siempre en la adolescencia una especie de extraño y suponerlo enfermo los inquieta. Suelen fluctuar entre la omnipotencia absoluta, con la desmentida de la situación, y la sensación de fragilidad y de muerte inminente» (Janin, 2020, p. 6).

El espacio virtual puede transformarse en un ámbito privilegiado para el encuentro con pares, a la vez que genera desencuentro con la mirada paterna. Aquí la intimidad sería un espacio sin padres. El ciberespacio y las redes sociales pueden constituirse en una variante de espacio transicional: funcionan "como un holding electrónico, una función maternante, de sostén, distribuido entre todos los contactos, usuarios o "amigos"» (Balaguer, 2012, p. 18).

Sin embargo, en algunos jóvenes la excesiva inmersión en el ciberespacio puede propiciar guiones de dependencia, conductas compulsivas (no tolerar la desconexión), de modo tal que la transicionalidad desaparece: no hay espacio entre el sujeto y el objeto, y aquel queda adherido a este, como una prótesis. Se pierde, de esta forma, la dimensión onírica de este ámbito, que se convierte en un terreno de huida. Así, François Marty y Sylvain Missonnier (2010-2011) sugieren que

el uso excesivo de los videojuegos, como el del alcohol o de otro tipo de sustancias, corresponde más bien a un modo singular de tratar las angustias de pérdida y de separación frecuentemente (re)vividas en la adolescencia, inclusive si son raramente reconocidas como tales. (párr. 12) 
Estos autores prefieren el término dependencia al de adicción, ya que muestra mejor no solamente un comportamiento, sino también un funcionamiento psíquico (Marty y Missonnier, 2010-2011). Frente a lo incontrolable y, eventualmente, angustioso de los cambios corporales, a través del juego y la virtualidad, los adolescentes intentan ser editores de su propia vida. Crean y ensayan alter egos, representados por diversos personajes o avatares, en una etapa en que ese cuerpo «adquiere un estatuto provisorio de extraterritorialidad» (Nin, 2010, p. 125), experimentado como yo y no-yo a la vez.

La fantasía de dominio, de puesta en juego de la omnipotencia, se escenifica en el mundo virtual a través del curioseo, al expandir los límites del cuerpo, al coquetear con atributos que aún no se manejan plenamente, al tener otro origen, al autoengendrarse, sin deber la existencia más que a uno mismo. De esta forma se combatiría el sentirse desvalido, desorientado, frente a la metamorfosis corporal y a la remodelación identificatoria. Así, la proyección, la omnipotencia, la negación, la escisión y la desmentida — defensas típicas de este período frente a la marea pulsional (Nin, 2004) — son las que coincidentemente suelen ponerse en juego frente a las situaciones de crisis importantes, en un crescendo que acompasa la gravedad de estas. La actual pandemia parece constituir un ejemplo privilegiado de estas situaciones.

Pero ¿hay lugar para lo novedoso y creativo en las situaciones de crisis? ¿Crisis puberal - crisis sanitaria?

Rodolfo Urribarri (2015) plantea que no todo lo que acontece en esta etapa es vivido con un sesgo negativo, como pérdida o renuncia. También emerge la posibilidad, el deseo y el disfrute de la adquisición de nuevas potencialidades que, a nuestro entender, podrían ensayarse primero en la realidad virtual, previo a su debut en el mundo real. Estos movimientos esperables, oscilantes entre lo progresivo y regresivo que caracterizan al 
adolescente, podrán tramitarse si hay adultos y sociedad que acompañe y sostenga.

En las décadas del cincuenta y sesenta, Erik Erikson (1971) acuñó el término moratoria social para dar cuenta de aquel tiempo muerto o, mejor, de trasbordo (Cao, 2009), compás de espera y preparación, en la búsqueda de la identidad. Este tiempo posibilita aplazar las consecuencias de nuestros actos y diferir las responsabilidades por ellos. Entendemos que el mundo virtual se constituye en otro campo de pruebas posible, donde esta moratoria también despliega.

Más allá del modo singular como cada joven habita las redes, en tanto visitante o residente virtual (White y Le Cornu, 2011), esta dimensión de nuestra cultura resulta insoslayable al acercarnos al intento por decodificar las adolescencias actuales. «Los jóvenes están en conexión, por defecto», como dice Roberto Balaguer (2012, p. 6). Tomar en cuenta esta dimensión se ha convertido en algo necesario para todas las franjas etarias, a fin de aportar al entendimiento del malestar civilizatorio actual y la tramitación de las concomitantes urgencias subjetivas.

La presencia ominosa de la enfermedad y la muerte, la constatación de que - a pesar de los avances científicos - no podemos aún curar la enfermedad provocada por el coronavirus, la imposibilidad o limitación del encuentro con otros, así como el confinamiento con la familia, parecen ratificar el pensamiento de Freud (1974), noventa años después de la publicación del El malestar en la cultura (1930). Basta recordar, como sintetizaba Manuel Laguarda (2020) en una conferencia reciente, las tres fuentes que generan ese malestar: «Somos finitos y mortales, el poder y la potencia de la naturaleza que nos limita y los vínculos sociales son necesarios e imprescindibles para sobrevivir, pero al mismo tiempo generan malestar». Pareciera que estas se ponen más en evidencia aun en la situación de pandemia. 
Estos malestares, también presentes en los procesos adolescentes, quedan amplificados en este contexto. La omnipotencia y la inmortalidad se ven jaqueadas por la presencia de la enfermedad y la finitud, así como por la pérdida de control en un cuerpo en permanente cambio. El deseo de autonomía y exploración del mundo y los vínculos se ve limitado por la cuarentena o la «nueva normalidad», y queda expuesta la ambivalencia entre la necesidad de alejamiento y la necesidad de sostén y refugio familiar. El mundo virtual, como hemos señalado, según el uso que se le dé, puede constituirse en una suerte de espacio transicional entre la realidad impuesta y la elección creativa de otras vías posibles, hasta estar preparado para afrontarla. Dependerá tanto de los recursos internos de los adolescentes, como de la facilitación o no del entorno.

\section{$\S$}

\section{REFERENCIAS BIBLIOGRÁFICAS}

Balaguer, R. (2012). La nueva matriz cultural. Pearson Education.

CAO, M. L. (2009). La condición Adolescente. Replanteo intersubjetivo para una psicoterapia psicoanalítica. Autopublicación.

CAO, M. L. (2020). Adolescencia y pandemia. ¿Repliegue narcisista o regresión? En F. Berardi, J. Besso, D. Cabrera, M. L. Cao, Y. Franco, F. Gargano, C. Guzzetti, R. Martins, I. Meler, E. Müller, M. C. Oleaga y D. Venturini, ¡Stop! Covid-19: ¿volver a la normalidad? (pp. 49-61). El psicoanalítico.

Corea, C. y Lewrowicz, I. (2013). Pedagogía del aburrido. Escuelas destituidas, familias perplejas. Paidós Educador. 
Costanzo, A. (2020). La Clínica en tiempos de Pandemia covid-19, nuestro Malestar contemporáneo. Aporte del Área de Adolescencias de AUDEPP. www.audepp.org/portal/wp-content/uploads/2020/04/LaCl\%C3\%ADnica-en-tiempos-de-Pandemia-COVID-19-nuestroMalestar-contempor\%C3\%A1neo.-A.-Costanzo..pdf

ERIKSON, E. H. (1971). Identidad, juventud y crisis. Paidós.

FREUD, S. (1974). El malestar en la cultura (1930). En Obras completas (vol. VIII, pp. 3017-3067). Biblioteca Nueva.

GARCíA, J. (2017). Intimidad-EXtimidad. www.apuruguay.org/sites/default/ files/Introducci\%C3\%B3n-a-INTIMIDAD-EXTIMIDAD-j-garcia.pdf JANin, B. (2020). Niños, adolescentes y padres en épocas de coronavirus. Actualidad Psicológica, XLV(494), 4-6. www.kennedy.edu.ar/ wp-content/uploads/2020/04/ACTUALIDAD-PSICOLOGICAABRIL-2020-AP-494.pdf

Laguarda, M. (2020, 18 de abril). Ser psicoanalista hoy: Desafios frente a las tensiones actuales [conferencia]. Ciclo 2020, El Malestar en la Cultura, AUDEPP.

Le Breton, D. (2014). Una breve historia de la adolescencia. Nueva Visión. Marty, F. y Missonnier, S. (2010-2011). Adolescencia y mundo virtual (trad. C. Costanzo Rondi). Études, 413(11), 473-484. www.cairn. info/revue-etudes-2010-11-page-473.htm

Nin, A. (2004). Algunas peculiaridades en el tratamiento psicoanalítico de pacientes adolescentes. Revista Uruguaya de Psicoanálisis, 99, 153168. www.apuruguay.org/revista_pdf/rup99/rup99-nin.pdf

Nin, A. (2010). Juegos de vida - juegos de muerte en la adolescencia. En S. Flechner (comp.), Psicoanálisis y adolescencia: dos temporalidades que se interpelan (pp. 121-135). Psicolibro.

Psicosol (2016). Exhibicionismo digital: El "Postureo". http://psicosol.es/ noticias/exhibicionismo-digital-el-postureo/ 
RANZANI, O. (2020, 27 de abril). El impacto de la cuarentena en la adolescencia. Página 12. www.pagina12.com.ar/262312-el-impacto-de-lacuarentena-en-la-adolescencia

RoJAs, M. C. (2015). Los adolescentes y los otros: clínica y complejidad. En S. Morici y G. Donzino (comps.), Problemáticas adolescentes. Intervenciones en la clínica actual (pp. 87-106). Noveduc.

Rodulfo, R. (2012). Padres e hijos en tiempos de la retirada de las oposiciones. Paidós.

URRIBARRI, R. (2015). Adolescencia y clínica psicoanalítica. Fondo de Cultura Económica.

SibiliA, P. (2010). Mutaciones de la subjetividad. En P. Sibilia, Ó. Sotolano, M. Rizzani, S. Topotosi, R. Espinosa, M. Koremblit, M. Lewcowicz, A. Granica, E. Muller y Y. Franco, La intimidad un problema actual en psicoanálisis (pp. 15-37). Psicolibro.

VIÑAR, M. (2010). Del mundo interno y las relaciones objetales a la prioridad del otro. En S. Flechner (comp.), Psicoanálisis y adolescencia: dos temporalidades que se interpelan (pp. 63-83). Psicolibro.

White, D. y Le Cornu, A. (2011). Visitors and Residents: A new typology for online engagement. First Monday, 16(9), 1-10. https://firstmonday.org/article/view/3171/3049

Winnicott, D. W. (1986). Realidad y juego. Gedisa. 